\title{
Indirect facilitation promotes macrophyte survival and growth in freshwater ecosystems threatened by eutrophication
}

\author{
Yoann Le Bagousse-Pinguet ${ }^{1 *} \dagger$, Pierre Liancourt ${ }^{2}$, Nicolas Gross ${ }^{3,4}$ and Dietmar Straile ${ }^{1}$ \\ ${ }^{1}$ Limnological Institute, University of Konstanz, Mainaustrasse 252, 78464 Konstanz, Germany; ${ }^{2}$ Department of \\ Biology, University of Pennsylvania, Philadelphia, PA 19104-6018, USA; ${ }^{3}$ CEBC-CNRS (UPR 1934), F-79360, \\ Beauvoir sur Niort, France; and ${ }^{4}$ INRA, USC CEBC, Numéro Codique F-79360, Beauvoir sur Niort, France
}

\begin{abstract}
Summary
1. Eutrophication is a major threat for freshwater ecosystems. Submerged aquatic plants (macrophytes) can maintain clear water conditions in eutrophic lakes by competing with phytoplankton for light and nutrients. The interactions between macrophytes and phytoplankton may lead to indirect facilitation among plants and the maintenance of high macrophyte diversities in eutrophic conditions. Nonetheless, the role of indirect facilitation in promoting macrophyte-dominated clear water states under eutrophication has never been demonstrated experimentally despite important implications for these ecosystems.

2. We predicted that (i) submerged aquatic plants buffer negative consequences of eutrophication by strongly affecting biotic (phytoplankton) and environmental conditions (light, nutrients) in the water column, (ii) competition with phytoplankton results in indirect facilitation among submerged aquatic plants, and (iii) the response to indirect facilitation depends on the tolerance of submerged aquatic plants to light attenuation by phytoplankton.

3. We experimentally simulated eutrophication through fertilization and manipulated the presence of neighbouring plants in a mesocosm. By manipulating the presence of neighbours with and without fertilization, we were able to test whether competitive or facilitative interactions occur during the eutrophication of lakes.

4. Fertilization caused turbid water states by increasing phytoplankton content and light attenuation. The presence of neighbouring plants reduced phytoplankton growth and promoted survival and biomass production of macrophytes under eutrophication.

5. Synthesis. Indirect facilitation among plants can buffer the direct negative interactions between aquatic plants and phytoplankton. Indirect facilitation may prevent the decline in aquatic plant diversity of freshwater ecosystems threatened by eutrophication. Because the experimental design used here is comparable to the manipulations frequently carried out across a wide range of terrestrial ecosystems, this study may contribute to the comparison of patterns and processes in aquatic and terrestrial environments.
\end{abstract}

Key-words: aquatic plant communities, community ecology, eutrophication, freshwater ecosystems, indirect facilitation, plant-plant interactions, species tolerance and deviation

\section{Introduction}

Nutrient enrichment (nitrogen and/or phosphorus) is one of the most important threats to biodiversity (Suding et al. 2005; Hillebrand et al. 2007), leading to major ecological changes in terrestrial and aquatic ecosystems on a global

${ }^{*}$ Correspondence author. E-mail: y.b-pinguet@orange.fr $\nmid$ Present address: University of Bordeaux, U.M.R. BIOGECO, Avenue des facultés, 33405 Talence, France. scale (Carpenter 2005). The consequence of eutrophication in shallow freshwater systems is not a linear function of the nutrient status (Scheffer et al. 1993). Rather, at a given ecological condition, two strikingly different alternative states can occur: the first is a clear water state with high biodiversity, dominated by submerged aquatic plants (macrophytes); the second is a more turbid state dominated by suspended phytoplankton (Scheffer et al. 1993; Jeppesen et al. 1997) and characterized by low macrophyte abundances (James et al. 2005; Sand-Jensen et al. 2008), 
following growth inhibition due to low light availability (Falkowski \& Raven 2007).

Macrophytes are proposed as key elements in the functioning of shallow lakes. They can promote clear water conditions in temperate lakes, through considerable nutrient uptake from the water column and limitation of phytoplankton growth (Scheffer et al. 1993; Jeppesen et al. 1997). In oligotrophic conditions, competition for nutrients among macrophyte species can be strong, resulting in local dominance of a few species (Gopal \& Goel 1993). Eutrophication promotes tall and fastgrowing species and can lead to increased direct competition among macrophytes for light and to competitive exclusion (e.g. Sand-Jensen et al. 2008). However, high macrophyte diversities can be observed in eutrophic conditions, declining only at the very end of the eutrophication gradient (Hillebrand et al. 2007; Sand-Jensen et al. 2008). As eutrophication increases, the maintenance of abundant and diverse macrophyte communities in clear water states may imply that indirect positive interactions (indirect facilitation) between submerged macrophytes arise from the complex network of negative interactions (i.e. competition) between macrophytes and the suspended phytoplankton (e.g. Scheffer et al. 1993). Facilitation among plants - a key process affecting community structure and ecosystem functioning (Brooker et al. 2008 for review; Gross et al. 2010a; Maestre et al. 2010) - may explain the maintenance of high macrophyte diversities in eutrophic freshwater ecosystems (Scheffer \& Carpenter 2003). However, there is, to the best of our knowledge, no experimental evidence demonstrating the role of indirect facilitation in promoting macrophyte-dominated clear water states under eutrophication.

The occurrence of indirect facilitation may depend on the interplay between two key components: (i) the ability of macrophytes to compete for nutrients with the phytoplankton, i.e. the ability of macrophytes to indirectly increase light availability (facilitative effect), and (ii) the macrophyte tolerance to shade from both their plant neighbours and phytoplankton, i.e. their ability to benefit from facilitation (facilitative response). Because macrophytes are likely to differ in their shade tolerance, their responses to indirect facilitation should be species-specific. Indeed, recent studies have shown for terrestrial plants that the outcome of plant-plant interactions (direction and intensity) depends on species-specific tolerances (Choler, Michalet \& Callaway 2001; Liancourt, Callaway \& Michalet 2005; see also Maestre et al. 2009 for a review). Within a community, only species that have reduced levels of success (hereafter termed species deviation) are likely to benefit from facilitation (e.g. Gross et al. 2010a). Applying this relationship between deviation and facilitation to freshwater ecosystems in the context of eutrophication implies that the most intolerant species to light attenuation by phytoplankton are also likely to be those most strongly facilitated by the indirect positive effect of macrophytes on light availability.

In this paper, we aim to experimentally demonstrate the role of facilitation as a key regulatory factor for the maintenance of submerged macrophyte performance (i.e. growth and survival) under eutrophication. We hypothesized that (i) macrophytes compete against each other in oligotrophic conditions, and (ii) they buffer eutrophication by strongly affecting the environmental conditions in the water column (nutrients, phytoplankton content and light availability). Therefore, we also predict that (iii) macrophytes positively affect each other (regarding growth and survival) under eutrophication, and (iv) their response to indirect facilitation depends on their tolerance to light attenuation by phytoplankton. To test these hypotheses, we ran a mesocosm experiment for two summers (2008 and 2009). We chose three widespread species of submerged aquatic macrophytes (Potamogeton perfoliatus, Potamogeton pectinatus and Myriophyllum spicatum) to study the outcome of plant-plant interactions under oligotrophic (non-fertilized) and eutrophic (fertilized) conditions.

\section{Materials and methods}

\section{TARGET SPECIES}

Submerged aquatic macrophytes are known to be a morphologically and functionally diverse group of species, for example, in their use of space and resources in sediment and water (Engelhardt \& Richie 2002). We chose three species of submerged aquatic macrophytes: the monocots $P$. perfoliatus $\mathrm{L}$. and $P$. pectinatus $\mathrm{L}$., and the dicot M. spicatum $\mathrm{L}$. for this study. They are all widely distributed in the northern hemisphere and have different morphologies (Gross, Feldbaum \& Choi 2002). They can all grow in monospecific or mixed stands. Potamogeton perfoliatus is a fast-growing species that produces dense canopies (Wolfer \& Straile 2004), occurs in a wide range of eutrophic conditions (Lehmann \& Lachavanne 1999) and is a dominant species in many lakes including Lake Constance in Central Europe (Scheffer, de Redellijkheid \& Noppert 1992; Schmieder 1997). We chose $P$. perfoliatus as our neighbour species because this species - due to its production of dense canopies, dominance and tolerance to eutrophication - is expected to strongly interact with the phytoplankton in the water column and to have direct and indirect effects on other macrophyte species.

To measure the competitive or facilitative neighbouring effect of $P$. perfoliatus, we selected three different target species: $P$. perfoliatus (to test intraspecific interactions) and $P$. pectinatus and $M$. spicatum (to test interspecific interactions). Potamogeton pectinatus and M. spicatum can persist in nutrient-rich lakes (Riis \& Sand-Jensen 2001; James et al. 2005). Potamogeton pectinatus has filiform leaf morphology and is considered to be a competitive species for nutrient uptake from the sediment (Engelhardt \& Richie 2002). Myriophyllum spicatum is a competitive species with rapid vegetative reproduction (Smith \& Barko 1990) and is present throughout freshwater ecosystems in the northern hemisphere. This species is an invasive exotic species that is currently a major nuisance in many lakes throughout North America (Chambers, Barko \& Smith 1993).

\section{THE EXPERIMENTAL DESIGN}

Our experiment to test the competitive or facilitative effects of $P$. perfoliatus neighbours under eutrophication lasted one growing season and was conducted in both 2008 and 2009 (Fig. 1a). Treatments of fertilization (low and high availability of nutrients) and neighbour presence (with and without $P$. perfoliatus) were crossed fully factorially to produce four treatment combinations: control 

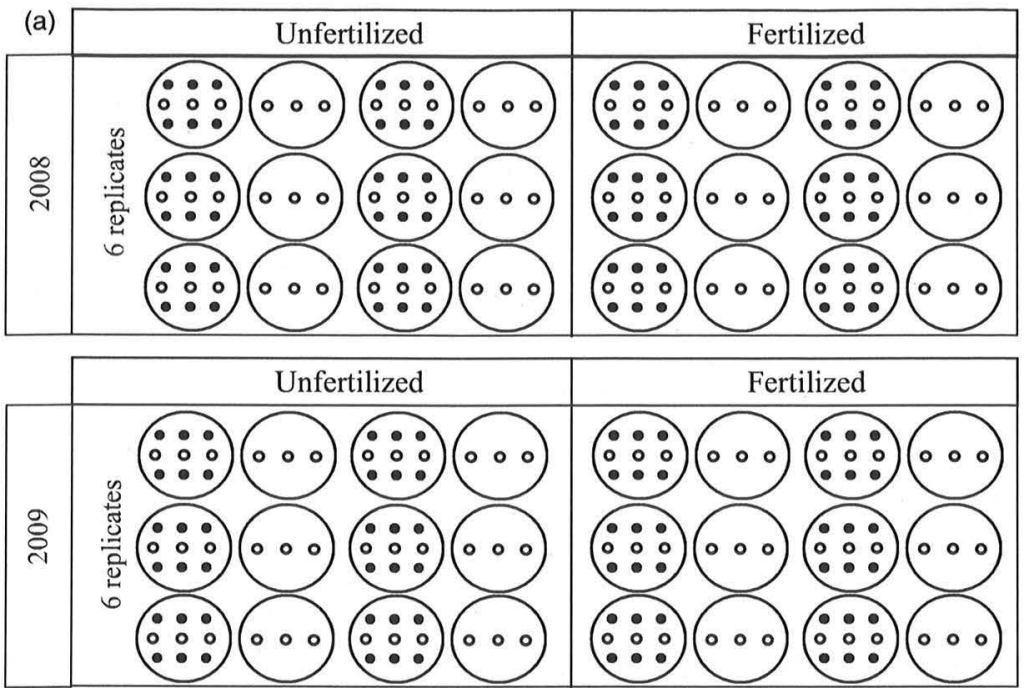

(b)

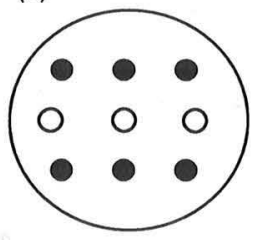

(c)

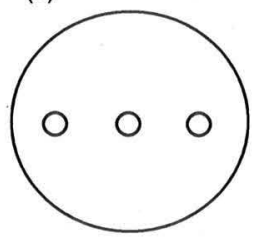

plots (i.e. no fertilization and no neighbour, con), plots with fertilization $(+F)$, plots with neighbours $(+n)$ and plots with fertilization and neighbours $(+F+n)$.

In each year, six plots (diameter $=0.5 \mathrm{~m}$ ) per treatment combination were established resulting in a total of 48 independent plots (six plots $\times$ four treatment combinations $\times 2$ years). Each plot was enclosed by a plastic bag (diameter $=0.5 \mathrm{~m}$, height $=0.9 \mathrm{~m}$; transparent Tricoron; RKW AG Rheinische Kunststoffwerke, Germany) to isolate sediment, water column and plants. All 48 plots received natural, unsterilized sediment from Lake Constance. All plots were placed in an outdoor mesocosm, with a minimum of $0.5 \mathrm{~m}$ space between each plot. Allocation of plots to particular treatments was random. The mesocosm was $10.5 \mathrm{~m}$ long, $5 \mathrm{~m}$ wide and $1.5 \mathrm{~m}$ high; the mesocosm was filled with an $c .90 \mathrm{~cm}$ depth of water from Lake Constance. Circulation of water within plots maintained homogeneous temperatures. Water temperature in the mesocosm showed seasonal dynamics similar to those in the lake's littoral zones (i.e. minimum and maximum temperatures during the experiment occurred in September $\left(14{ }^{\circ} \mathrm{C}\right)$ and June $\left(23^{\circ} \mathrm{C}\right)$, respectively), but no difference between years occurred $(P>0.05)$.

To test the competitive or facilitative effect of $P$. perfoliatus neighbours (i.e. neighbour presence), monospecific stands (henceforth matrices) of $P$. perfoliatus were established $(+\mathrm{n}$ and $+\mathrm{F}+\mathrm{n}$ ) in early May 2008 and again in early May 2009 (Fig. 1b). We used apical shoots of established plants, reflecting the predominant vegetative propagation in perennial submerged aquatic plants (Engelhardt \& Richie 2002). Apical shoots were collected in early May 2008 and 2009 in Lake Constance. Six apical shoots of similar size (20 cm long) were randomly selected and planted in a regular pattern in the plots. This density reflects the shoot density observed at the beginning of the growing season in Lake Constance (Wolfer \& Straile 2004). Plots were grown for 1.5 months to achieve sufficient biomass to mimic the biomass of $P$. perfoliatus under field conditions (see Wolfer \& Straile 2004). Bare soil plots (con and $+F$ ) were also installed at this time to
Fig. 1. Schematic representations of (a) the detailed experimental design, (b) matrices with the six shoots of Potamogeton perfoliatus (filled circles) (neighbours) and the three individual targets of each species (open symbols) and (c) bare soil plots (no neighbours) with the three individual targets (open symbols). Note that plots are grouped by fertilization treatments in the figure for illustrative purposes. In reality, treatments were randomly assigned to plots each year (see more details in the methods).

test the performance of isolated target species individuals (see below for measurements of performance; Fig. 1c).

To test the effect of eutrophication, $+\mathrm{F}$ and $+\mathrm{F}+\mathrm{n}$ treatment combinations were prepared by adding one 400 -g dose of commercial tree and shrub slow-release fertilizer $(15 \% \mathrm{~N}, 8 \% \mathrm{P}, 14 \% \mathrm{~K}, 2 \% \mathrm{Mg}$ : Compo) mimicking the high nutrient treatment of Cronin \& Lodge (2003).

Target individuals of each species were planted in mid-June. Hence, the experimental duration was from 10 June to 21 September in 2008 (104 days) and from 15 June to 21 September in 2009 (99 days). In each plot, one individual of each target species ( $P$. perfoliatus, $P$. pectinatus and $M$. spicatum) was planted resulting in altogether $48 \times 3=144$ target individuals. Before planting, shoots of each target species were standardized by cutting them back to a height of $5 \mathrm{~cm}$. Target individuals were planted either within the matrices $(+\mathrm{n}$ and $+\mathrm{F}+\mathrm{n}$ treatment combinations) or in the centre of the bare soil plots (con and $+\mathrm{F}$ treatment combinations). We assumed that, during the experiment, interactions between the three individuals of the target species were negligible due to their small biomass as compared to the biomass of the $P$. perfoliatus matrices.

\section{DATA COLLECTION}

\section{Impact of treatments on water quality and neighbouring plants}

We quantified the interacting effects of fertilization and neighbour presence on the water column (water quality). We measured chlorophyll- $a$ concentration (Chl- $a$ ) - a proxy for phytoplankton content and considered as one of the most important compounds determining light attenuation in water due to phytoplankton (Scheffer 1998) - light attenuation (2008 and 2009) and nutrient concentrations (total phosphorus, total nitrogen) (only for 2009). 
We measured Chl- $a$ concentrations within the water columns on 15 September 2008 and 16 September 2009 with a multichannel fluorescent probe (Fluoroprobe, bbe molderenke, Kiel, Germany). No cleaning of plots to prevent algal build-up was performed during the experiment.

Light measurements were taken at the end of the experiments (15 September 2008 and 16 September 2009, respectively) within the water columns to test the effects of fertilization, neighbour presence and their interaction. We quantified the light attenuation in each plot by the following relationship:

Light attenuation $=\left[1-\left(\right.\right.$ light $_{\text {ground }} /$ light $\left.\left._{\text {water surface }}\right)\right] \times 100$

All light measurements were taken with a LI-1400 Quantum Sensor (LI-COR ${ }^{\circledast}$, LI-COR Corporate Office, Lincoln, NE, USA) under full sun between 11 AM and 2 PM for six random points per plot.

We sampled the water of each plot and analysed total nitrogen and total phosphorus content on the 15 September 2009 using a Technicon Autoanalyser II (Bran and Luebbe, Delavan, Wisconsin) after digestion with potassium persulfate.

We measured the total biomass of neighbouring plants $(P$. perfoliatus matrices) to assess the impact of eutrophication (fertilization) on the abundance of submerged macrophytes, commonly decreasing in turbid states (James et al. 2005; Sand-Jensen et al. 2008). Total biomass of neighbouring plants was recorded on the 21 September 2008 and the 21 September 2009 in all plots. Neighbouring plants were harvested, and their biomass was determined by drying them at $70{ }^{\circ} \mathrm{C}$ for $72 \mathrm{~h}$ before weighing.

\section{Impact of treatments on targets species}

Target species performances (survival and biomass) without neighbours were used to assess individual responses to eutrophication. Survival and biomass for all treatments were recorded 1 year apart on 21 September for 2008 and 2009. Target plants were harvested, and their biomass was determined by drying them at $70{ }^{\circ} \mathrm{C}$ for $72 \mathrm{~h}$ before weighing. Survival of target plants was calculated as a percentage of surviving individuals for each species per fertilization treatment per year, and biomass was averaged per species, per fertilization treatment and per year.

We estimated the tolerance of the three target species to eutrophication. Eutrophication by fertilizer application and subsequent phytoplankton development may negatively affect the performance (survival and growth) of species intolerant to light attenuation. To quantify the tolerance of the target species to light attenuation due to eutrophication, we calculated the natural-log-transformed response

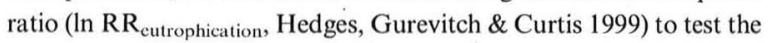
deviation (i.e. reduction in success). To estimate target species' tolerances solely to eutrophication, In $\mathrm{RR}_{\text {cutrophication (Hedges, Gurevitch }}$ \& Curtis 1999) was calculated using both survival and biomass data. $\mathrm{Ln} \mathrm{RR}_{\text {eutrophication }}$ compares the performance of target species grown without neighbours in the control plots (con) and the fertilized plots $(+F)$ :

$$
\begin{aligned}
& \ln \mathrm{RR}_{\text {eutrophication }} \\
& \quad=\ln \frac{\text { Target performances in the fertilized plots }(+F)}{\text { Average of target performances in the control plots (con) }}
\end{aligned}
$$

The response of the three target species to biotic interactions (competition or facilitation), i.e. the proportional change in performance (survival or biomass) due to the presence of neighbours, was quantified separately for unfertilized and fertilized plots using the natural-log-transformed response ratio ( $\ln R R_{\text {neighbours }}$ ):

$$
\begin{aligned}
& \ln \mathrm{RR}_{\text {neighbours }} \\
& \quad=\ln \frac{\text { Target performances with } P \text {. perfoliatus matrix }}{\text { Average of target performances without } P \text {. perfoliatus matrix }}
\end{aligned}
$$

Values of response ratios are symmetrical around 0 . No difference from 0 for $\ln \mathrm{RR}_{\text {cutrophication }}$ and $\ln \mathrm{RR}_{\text {neighbours }}$ indicates that fertilizer application and the presence of neighbours had no effect on target performances, respectively. Negative values of $\ln R_{\text {eutrophication }}$ indicate that fertilizer application had a negative effect on target performances (intolerant species to light attenuation), i.e. deviation by eutrophication, whereas positive values indicate a benefit of the fertilization treatment on target performances. Negative values of $\mathrm{ln}$ $\mathrm{RR}_{\text {neighbours }}$ indicate competition among plants, whereas positive values indicate facilitation.

\section{DATA ANALYSIS}

\section{Impact of treatments on water quality and neighbouring plants}

Chl- $a$ and light attenuation were analysed using a three-way ANOvA with year, neighbour ( $P$. perfoliatus matrices) and fertilization as fixed factors. Data from 2009 for total phosphorus, total nitrogen and N/P were analysed using a two-way ANOva with neighbour presence and fertilization as fixed factors. Biomass of neighbouring plants was analysed for both years using a two-way ANOva model with fertilization and year as fixed factors. Chl- $a$ concentration, light attenuation, total phosphorus, total nitrogen, N/P and biomass of neighbouring plants were log-transformed before analyses. Residuals of all statistical models met parametric assumptions of normality and homogeneity.

\section{Impact of treatments on targets species}

Survival and biomass without neighbours and $\ln R_{R_{\text {neighbour }}}$ survival and $\ln \mathrm{RR}_{\text {neighbour }}$ biomass were analysed using a three-way ANOVA model with year, species and fertilization as fixed factors. Ln $R R_{\text {eutrophication }}$ survival and $\ln \mathrm{RR}_{\text {eutrophication }}$ biomass were analysed using a two-way ANOva model with year and species as fixed factors. One-sample $t$-tests were used to test significant differences from 0 for In $\mathrm{RR}_{\text {cutrophication }}$ and $\ln \mathrm{RR}_{\text {neighbour. }}$

Survival and biomass were log-transformed before analyses. Residuals of all statistical models met parametric assumptions of normality and homogeneity. All analyses were performed using JMP software 5.0.1 (SAS Institute, Cary, NC, USA)

\section{Results}

\section{IMPACT OF TREATMENTS ON WATER QUALITY AND NEIGHBOURING PLANTS}

Fertilization strongly increased the Chl- $a$ concentration, the light attenuation, total phosphorus, total nitrogen (Table 1, Fig. 2a-d) and the molar N/P ratio (Table 1). The presence of neighbours reduced the effect of fertilization, as demonstrated by significant interaction terms in the statistical models for Chl- $a$, light attenuation, total nitrogen (Table 1, Fig. 2a,b,d) 
and N/P (Table 1). The presence of neighbours increased total phosphorus in the water column, but no interaction with fertilization occurred (Table 1, Fig. 2c). The presence of neighbours limited the increase in Chl- $a$ with fertilization (Fig. 2a) and, consequently, also indirectly limited light attenuation (Fig. 2b). Within the $+\mathrm{F}+\mathrm{n}$ treatment combination, neighbouring plant biomass significantly affected Chl- $a$ (Chl- $a$ con- centration $=114.01-9.68 \times$ neighbouring

biomass, $\mathrm{n}=12, \mathrm{R}^{2}=0.40, P=0.04$, Fig. $2 \mathrm{e}$ ) and light attenuation (light attenuation $=91.19-0.92 \times$ neighbouring biomass, $\mathrm{n}=12, R^{2}=0.51, P=0.016$, Fig. 2f). Chl- $a$ concentration and light attenuation did not differ between years, indicating a similar response of variables for the two consecutive years (Table 1). Likewise, the effects of fertilization and neighbours

Table 1. Results of the three-way anova models for the effects of year (Y.), neighbour presence (n.), fertilization (F.) and their interactions on the phytoplankton content (Chl-a) and the light interception and the results of the two-way anova models for the effects of neighbour presence (n.), fertilization (F.) and their interactions on total phosphorus, total nitrogen and N/P ratio. Significant effects $(P<0.05)$ are indicated in bold

\begin{tabular}{|c|c|c|c|c|c|c|c|c|c|c|c|c|c|c|c|}
\hline & \multicolumn{3}{|c|}{ Chl- $a$} & \multicolumn{3}{|c|}{ Light interception } & \multicolumn{3}{|c|}{ Total phosphorus } & \multicolumn{3}{|c|}{ Total nitrogen } & \multicolumn{3}{|c|}{$\mathrm{N} / \mathrm{P}$ ratio } \\
\hline & d.f. & $F$ & $P$ & d.f. & $F$ & $P$ & d.f. & $F$ & $P$ & d.f. & $F$ & $P$ & d.f. & $F$ & $P$ \\
\hline Y. & 1 & 0.25 & 0.62 & 1 & 0.39 & 0.53 & - & - & - & - & - & - & - & - & - \\
\hline n. & 1 & 3.49 & 0.07 & 1 & 0.68 & 0.41 & 1 & 6.66 & 0.018 & 1 & 0.002 & 0.96 & 1 & 0.68 & 0.41 \\
\hline Y. $\times$ n. & 1 & 0.51 & 0.48 & 1 & 0.59 & 0.45 & - & - & - & - & - & - & - & - & - \\
\hline F. & 1 & 64.88 & $<0.0001$ & 1 & 127.02 & $<0.0001$ & 1 & 23.75 & $<0.0001$ & 1 & 130.37 & $<0.0001$ & 1 & 14.83 & 0.0001 \\
\hline Y. $\times$ F. & 1 & 0.72 & 0.40 & 1 & 0.06 & 0.80 & - & - & - & - & - & - & - & - & - \\
\hline n. $\times$ F & 1 & 4.28 & 0.046 & 1 & 53.94 & $<0.0001$ & 1 & 1.83 & 0.19 & 1 & 9.76 & 0.005 & 1 & 7.30 & 0.01 \\
\hline $\mathrm{Y} . \times \mathrm{n} . \times \mathrm{F}$ & 1 & 0.27 & 0.61 & 1 & 0.01 & 0.93 & - & - & - & - & - & - & - & - & - \\
\hline Error (model) & 40 & & & 40 & & & 20 & & & 20 & & & 20 & & \\
\hline
\end{tabular}
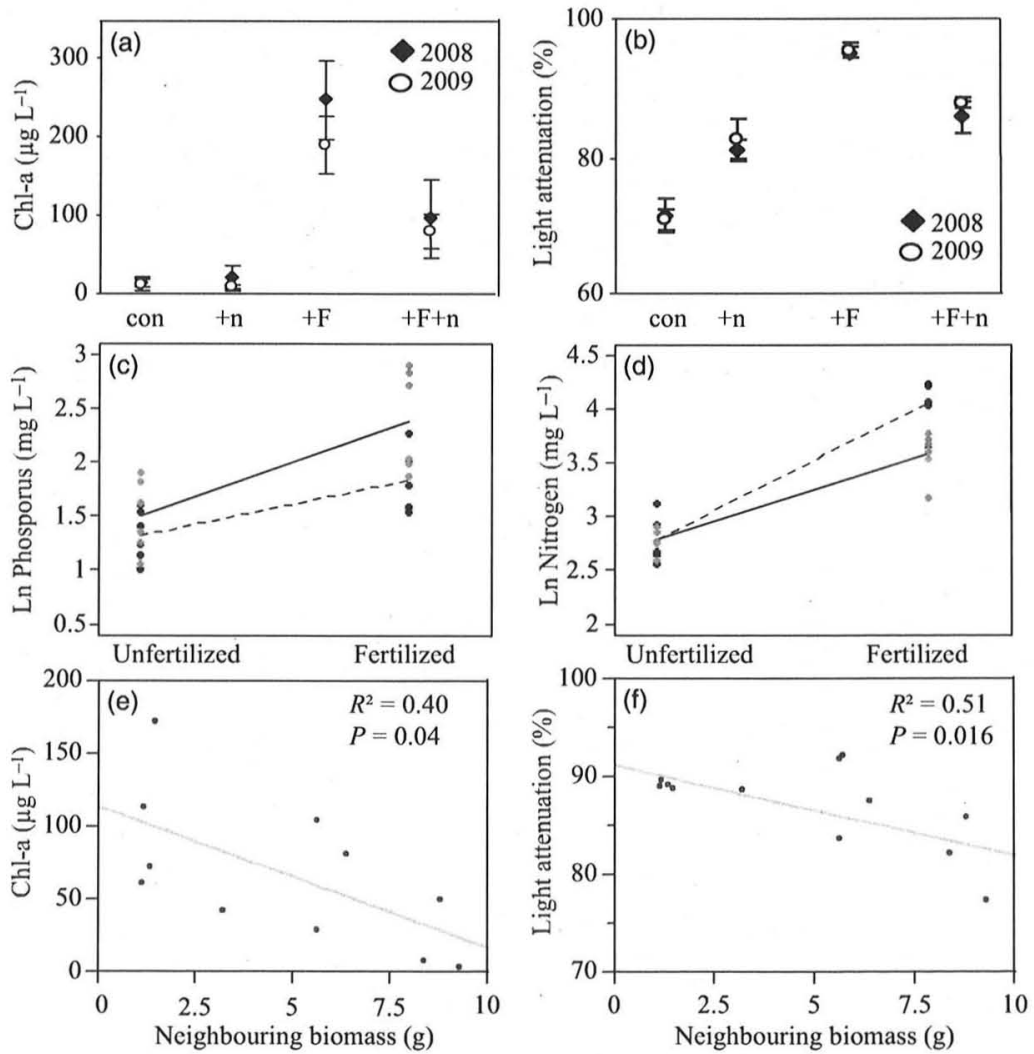

Fig. 2. The effects of fertilization and neighbouring treatments on (a) phytoplankton response, (b) light attenuation, (c) phosphorus and (d) nitrogen contents $(n=6)$. The results in Fig. 1a,b are represented for the control (con), with neighbours $(+n)$, fertilized without neighbours $(+\mathrm{F})$ and fertilized with neighbours $(+\mathrm{F}+\mathrm{n})$ for 2008 (black rhombus) and 2009 (empty circle). Data and mean responses of phosphorus (Fig. 1c) and nitrogen contents (Fig. 1d) for both unfertilized and fertilized treatments are shown with neighbouring plants (solid line and grey dots) and without (dashed line and black dots). Effects of neighbouring plant biomass in fertilized treatment $(+\mathrm{F}+\mathrm{n})$ are shown on $(\mathrm{e})$ phytoplankton content (direct effect) and (f) light attenuation (indirect effect). 
on both Chl- $a$ and light attenuation did not differ between years (Table 1).

Fertilization decreased neighbouring plant biomass by a factor of $1.6\left(+\mathrm{n}: 7.74 \pm 0.66 \mathrm{~g},+\mathrm{F}+\mathrm{n}: 4.86 \pm 0.38 \mathrm{~g}, F_{1,20}=\right.$ $9.41, P=0.006)$. Neither a year effect solely $\left(F_{1,20}=2.54\right.$, $P>0.05)$ nor a statistical interaction with fertilization occurred $\left(F_{1,20}=1.13, P>0.05\right)$, indicating a similar effect of fertilization on neighbouring plant biomass between the two consecutive years.

\section{IMPACT OF TREATMENTS ON TARGETS SPECIES}

Without the presence of neighbours, fertilization significantly decreased both survival and biomass of the three target species (Table 2, Fig. 3a,b). Negative values of $\ln R_{\text {eutrophication }}$ survival and $\ln \mathrm{RR}_{\text {cutrophication }}$ biomass occurred for all species reflecting the strong negative effects of fertilization on target species performance (Fig. 3c,d). Because no species effect was detected for $\ln R R_{\text {eutrophication }}$ survival and $\ln R_{\text {eutrophication }}$ biomass (Table 2), data from the three target species were pooled to test whether the $\ln \mathrm{RR}_{\text {eutrophication }}$ survival and $\ln$

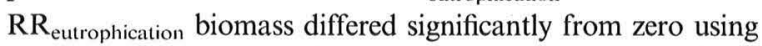
one-sample $t$-tests. Negative $\operatorname{Ln} \mathrm{RR}_{\text {eutrophication values were sig- }}$ nificantly different from zero regarding survival (one-sample $t$-test: $\quad t=-8.09, \quad P<0.0001, \quad$ Fig. $3 c)$ and biomass ( $t=-5.72, P=0.0001$, Fig. $3 \mathrm{~d}$ ), indicating that the performance of all target species was affected by eutrophication, and thus, species have reduced levels of success in term of survival and biomass. No year effect or interaction with other treatments was detected for survival without neighbours or for $\ln$ $\mathrm{RR}_{\text {eutrophication }}$ survival (Table 2). In contrast, a year effect was

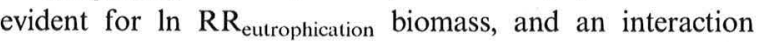
between year and species was found for biomass without neighbours.

There were no effects of species identity or any interaction effects of identity with fertilization on $\ln \mathrm{RR}_{\text {neighbour }}$ survival or $\ln \mathrm{RR}_{\text {neighbour }}$ biomass (Table 2). Thus, species were pooled to test whether $\ln R R_{\text {neighbour }}$ survival and $\ln R R_{\text {neighbour }}$ biomass differed significantly from zero with and without fertilization using one-sample $t$-tests. Without fertilization,
In $\mathrm{RR}_{\text {neighbour }}$ values for both survival and biomass were negative $\left(\ln \mathrm{RR}_{\text {neighbour }}\right.$ survival $<0, t=-2.58, P=0.014$, Fig. 3e; ln $\mathrm{RR}_{\text {ncighbour }}$ biomass $<0, t=-7.76, P<0.0001$, Fig. 3f), indicating that target species experienced competition. Fertilization significantly increased values of $\ln R_{R_{\text {neighbour }}}$ survival and $\ln \mathrm{RR}_{\text {neighbour }}$ biomass (Table 2), highlighting that all target species experienced a change in plant interactions (Fig. 3e,f). As a result, $\ln \mathrm{RR}_{\text {neighbour }}$ was positive for both survival (ln $\mathrm{RR}_{\text {neighbour }}$ survival $>0, t=3.24, P=0.003$, Fig. 3e) and biomass ( $\ln \mathrm{RR}_{\text {neighbour }}$ biomass $>0, t=3.18$, $P=0.005$, Fig. 3f), indicating facilitation in the fertilized plots.

\section{Discussion}

Eutrophication commonly results in increased competition and species loss (e.g. Suding et al. 2005; Sand-Jensen et al. 2008). Although the role of positive interactions in shaping communities has been recognized (see Brooker et al. 2008 for a review), there is, to the best of our knowledge, no evidence of their impact in aquatic ecosystems threatened by eutrophication. Here, we demonstrated experimentally the effect of indirect facilitation in maintaining individual performance (survival and biomass production) of three macrophyte species under eutrophication. Our results support the proposal by Scheffer et al. (1993) and Scheffer \& Carpenter (2003) that 'submerged plants can enhance water clarity, thus improving the light for their underwater growth' and highlight the importance of positive interactions between macrophytes in mediating the effect of eutrophication in freshwater ecosystems. Furthermore, one of the challenges of studying facilitation is reproducing stressful conditions in which positive interactions tend to occur. Greenhouse and controlled experiments typically place plants in idealized conditions where facilitation is unlikely to occur. Here, we demonstrate the occurrence of positive interactions in a controlled experiment (see also Callaway \& King 1996; Espeland \& Rice 2007 in greenhouse experiments), highlighting a promising approach for further investigations into the role of facilitation in freshwater communities and ecosystems.

Table 2. Results of the three-way Anova models for the effects of year (Y.), species (S.), fertilization (Fert.) and their interactions on the survival and the biomass of the three target species without neighbours (left) and the $\ln \mathrm{RR}_{\text {neighbours }}$ (right) and the results of the two-way anova model for the effects of year (Y.), species (S.) and their interactions on the $\ln \mathrm{RR}_{\text {eutrophication. }}$ Significant effects $(P<0.05)$ are indicated in bold

\begin{tabular}{|c|c|c|c|c|c|c|c|c|c|c|c|c|c|c|c|c|c|c|}
\hline & \multicolumn{3}{|c|}{ Survival } & \multicolumn{3}{|c|}{ Biomass } & \multicolumn{3}{|c|}{$\begin{array}{l}\text { In } \mathrm{RR}_{\text {eutrophication }} \\
\text { survival }\end{array}$} & \multicolumn{3}{|c|}{$\begin{array}{l}\text { In } \mathrm{RR}_{\text {eutrophication }} \\
\text { biomass }\end{array}$} & \multicolumn{3}{|c|}{$\begin{array}{l}\text { In } \mathrm{RR}_{\text {neighbours }} \\
\text { survival }\end{array}$} & \multicolumn{3}{|c|}{$\begin{array}{l}\text { In } \mathrm{RR}_{\text {neighbours }} \\
\text { biomass }\end{array}$} \\
\hline & d.f. & $F$ & $P$ & d.f. & $F$ & $P$ & d.f. & $F$ & $P$ & d.f. & $F$ & $P$ & d.f. & $F$ & $P$ & d.f. & $F$ & $P$ \\
\hline Y. & 1 & 0.96 & 0.332 & 1 & 1.15 & 0.291 & 1 & 0.13 & 0.719 & 1 & 11.44 & 0.012 & 1 & 2.53 & 0.117 & 1 & 0.12 & 0.73 \\
\hline S. & 2 & 1.38 & 0.259 & 2 & 26.79 & $<0.0001$ & 2 & 0.71 & 0.494 & 2 & 1.58 & 0.272 & 2 & 0.18 & 0.834 & 2 & 0.61 & 0.546 \\
\hline $\mathrm{Y} . \times \mathrm{S}$ & 2 & 0.32 & 0.728 & 2 & 1.04 & 0.366 & 2 & 0.31 & 0.737 & 2 & 1.61 & 0.245 & 2 & 0.17 & 0.841 & 2 & 4.01 & 0.026 \\
\hline $\mathrm{F}$ & 1 & 56.28 & $<0.0001$ & 1 & 58.81 & $<0.0001$ & - & - & - & - & - & - & 1 & 16.12 & 0.0002 & 1 & 52.74 & $<0.0001$ \\
\hline $\mathrm{Y} . \times \mathrm{F}$ & 1 & 0.11 & 0.745 & 1 & 8.64 & 0.006 & - & - & - & - & - & - & 1 & 0.10 & 0.749 & 1 & 1.63 & 0.209 \\
\hline S. $\times F$ & 2 & 1.38 & 0.259 & 2 & 1.46 & 0.246 & - & - & - & - & - & - & 2 & 0.74 & 0.477 & 2 & 1.32 & 0.278 \\
\hline $\mathrm{Y} . \times \mathrm{S} . \times \mathrm{F}$ & 2 & 0.74 & 0.479 & 2 & 3.44 & 0.072 & - & - & - & - & - & - & 2 & 0.81 & 0.451 & 2 & 0.29 & 0.596 \\
\hline Error (model) & 60 & & & 36 & & & 66 & & & 7 & & & 60 & & & 39 & & \\
\hline
\end{tabular}


Survival

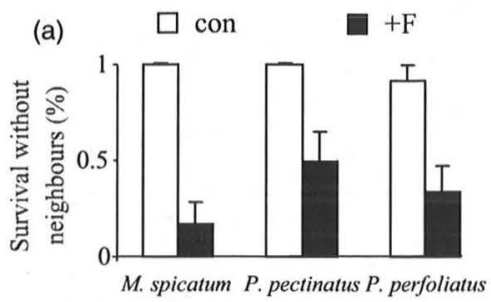

(c)

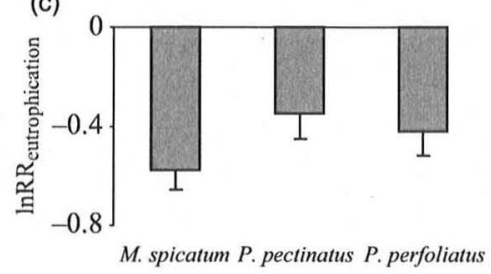

(e)

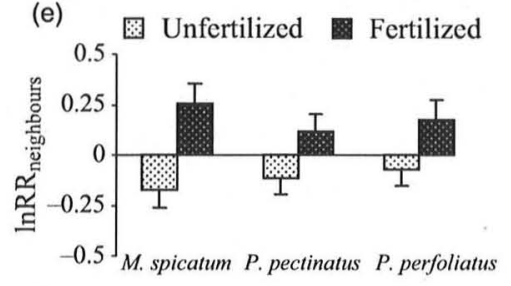

Biomass

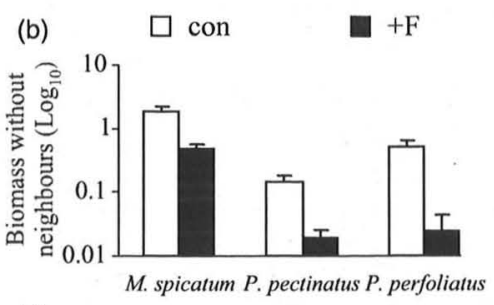

(d)

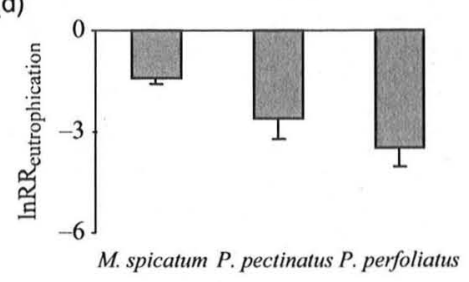

(f)

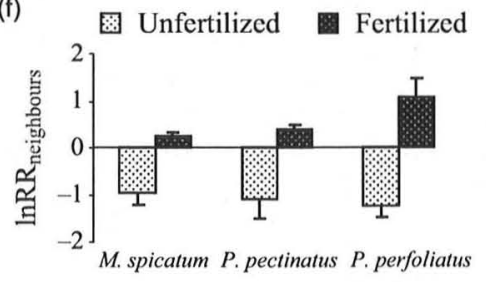

Fig. 3. The effects of fertilization on the survival (a) and the biomass (b) without neighbours of the three target species (Myriophyllum spicatum: M. spic., Potamogeton pectinatus: $P$ pect. and Potamogeton perfoliatus: $P$. perf.) (means $\pm \mathrm{SE}$ ) in unfertilized (white bars) and fertilized conditions (black bars), the $L n R R_{\text {eutrophication }}$ for survival (c) and for biomass (d) (grey bars) and the $\ln R_{\text {neighbours }}$ for survival (e) and for biomass (f) in unfertilized (white bars with dots) and fertilized conditions (black bars with dots) $(n=6)$.

Fertilization has a complex effect on the water column by altering the outcomes of biotic interactions. Fertilization resulted in a substantial burst of phytoplankton growth $\left(224 \pm 31.75 \mu \mathrm{g} \mathrm{Chl}-a\right.$. $\left.\mathrm{L}^{-1}\right)$, increasing light attenuation and the N/P ratio (above the Redfield ratio: $P$ limitation, Redfield 1958), negatively impacting neighbouring plants and resulting in a heavily eutrophic (eu-hypertrophic) state. Without neighbouring plants, survival and biomass of all the target species were strongly affected by fertilization (Fig. 3c,d). These results are consistent with previous studies showing that an increased nutrient loading and the subsequent increase in light attenuation due to the growth of phytoplankton (Falkowski \& Raven 2007) can impact submerged aquatic plant communities (James et al. 2005; Sand-Jensen et al. 2008).

However, neighbours limited the increase in total nitrogen in the fertilized treatment (Fig 2d) through a considerable nitrogen uptake from the water column (see also Meijer $e t$ al. 1994). Although neighbouring plants increased total phosphorus, likely due to their capacity to release it from the sediment to the water column (Stephen, Moss \& Phillips 1997), this was not translated into an increase in phytoplankton. The molar $\mathrm{N} / \mathrm{P}$ ratio in the $+\mathrm{F} /+\mathrm{n}$ treatment $(+\mathrm{F}+\mathrm{n}: 12.35 \pm 3.50)$ was below the Redfield ratio; this suggests a nitrogen limitation for phytoplankton growth, which is often observed at high phosphorus concentrations in freshwater systems (McCauley, Downing \& Watson 1989; Moss, McGowan \& Carvalho 1994). Hence, the decrease in total nitrogen limited phytoplankton growth and light attenuation, leading to indirect facilitation among macrophytes. Indirect facilitation promoted the performance of target plants under eutrophication and thus can be considered an important driver for aquatic plant communities.

Besides phytoplankton, other algae such as periphyton developing on macrophyte leaves likely played a role in our experiment for macrophyte responses. By increasing light attenuation at the leaf surface, periphyton may have contributed to the decrease in neighbour performance and effect on target plants under eutrophication. However, neighbours were still able to indirectly facilitate target plants.

Interspecific ( $M$. spicatum and $P$. pectinatus) and intraspecific ( $P$. perfoliatus) positive interactions increased with increasing light stress, i.e. productivity. These results apparently contradict the prediction that competition increases with productivity (e.g. Grime 1973; Hautier, Niklaus \& Hector 2010 in terrestrial systems; Sand-Jensen et al. 2008 in aquatic systems). However, similar changes in plant interactions with increased productivity can be observed in terrestrial ecosystems. First, these changes can result from interactions with other trophic levels, such as herbivores (Bertness \& Callaway 1994). Highly productive environments generally support higher herbivore densities (e.g. Oksanen \& Oksanen 2000). Increased herbivore densities limit light competition from tall, dominant species (Grime 1973; Connell 1978), i.e. alleviate competitive exclusion (release from competition, Grubb 1977). Secondly, changes in plant interactions can result from indirect facilitative effects. At high herbivore densities, indirect 
facilitation can occur as a result of neighbouring plant protection (Bertness \& Callaway 1994; Brooker \& Callaghan 1998), through either the occurrence of biotic refuges (physical barrier such as spine presence, Callaway 1995) or associational avoidance (see Milchunas \& Noy-Meir 2002 for a review). Indirect facilitation by associational avoidance has also been recently demonstrated among macrophytes in heavily grazed freshwater ecosystems (Le Bagousse-Pinguet, Gross \& Straile 2011).

In contrast to these commonly discussed mechanisms of facilitation in productive environments, the facilitative plantplant interactions occurring in response to fertilization in our study are the result of a network of negative interactions for both light and nutrient acquisition. Similar mechanisms may occur along productivity gradients in terrestrial systems, particularly where water is a non-limiting resource and where productivity is mainly driven by nutrient availability (e.g. Tilman 1982; Gross et al. 2009; Liancourt, Viard-Cretat \& Michalet 2009). In such terrestrial systems, slow growing species could prevent the establishment of fast-growing, competitive species in a fashion similar to that observed in our freshwater system (e.g. Liancourt, Viard-Cretat \& Michalet 2009; Gross et al. 2010b): slow growing species (analogous to macrophytes) limit nutrient availability for fast-growing species (analogous to phytoplankton) and thus retain their dominance despite increasing nutrient availability. Notably, indirect interactions are mostly studied across trophic levels (as discussed above). Indirect interactions within the same trophic level are generally understudied and, as a consequence, potentially underestimated. Our results highlight that indirect interactions within a trophic level can strongly affect the outcome of plant-plant interactions and that further-studies should examine these potential indirect effects as important processes for the structuring of plant communities.

Our study highlights that deviation ( $\left.L n R_{\text {eutrophication }}\right)$, i.e. the level of stress experienced by a species, mirrors the positive outcome of plant interactions. The three target species were equally deviated due to induced light stress by phytoplankton development in response to eutrophication (see biotic induced stress in Grime 1973). Likewise, biotic interactions shifted for all target species in a similar way, i.e. from negative to positive interactions with eutrophication. Species' responses to plant interactions have been shown to be strongly influenced by their stress-tolerance abilities (i.e. shade tolerance in our case) (Liancourt, Callaway \& Michalet 2005). The possibility of using a species' sensitivity to stress or disturbance to predict the outcome of plant interactions was first proposed with respect to abiotic severity gradients. Previous studies in subalpine (Choler, Michalet \& Callaway 2001; Gross et al. 2010a) and species-rich calcareous grasslands (Liancourt, Callaway \& Michalet 2005) have illustrated the relationship between deviation and responses to plant interactions with increasing abiotic stress. Here, we suggest that it equally applies in the context of stress induced by an external biotic agent (i.e. phytoplankton). A similar pattern has also been recently reported in forests in which trees facilitate seedlings by competing with vegetation growing underneath the canopy of adults (Saccone et al. 2010).
Declines in species richness and abundance with nutrient loading have been reported in terrestrial (e.g. Suding et al. 2005) and aquatic ecosystems (e.g. Sand-Jensen et al. 2008). These declines in species richness are usually attributed to an increase in competitive interactions in both terrestrial and aquatic systems, i.e. competitive exclusion (Suding et al. 2005). However, fertilization has been recently shown to enhance species richness in aquatic ecosystems in meso-eutrophic conditions (James et al. 2005; Hillebrand et al. 2007) with a drop in species richness only occurring in highly eutrophic conditions (e.g. Sand-Jensen et al. 2008). The occurrence of indirect facilitation may explain such a pattern. The net positive outcome of plant interactions observed in our fertilized treatment illustrates that the benefit of indirect facilitation overcomes the negative effects of increased competition between submerged plants and light stress induced by phytoplankton. Facilitation among macrophyte species may prevent the decline in species richness and abundance due to competitive exclusion and increasing competition-induced stress under eutrophication as observed along abiotic stress gradients in terrestrial ecosystems (e.g. Hacker \& Gaines 1997; Michalet et al. 2006; Holmgren \& Scheffer 2010). Species richness of terrestrial ecosystems is also known to drop at the very end of stress gradients, partly due to the collapse of positive interactions (Michalet et al. 2006). Further experiments are needed in aquatic ecosystems to test whether the drop in species richness occurring at the very end of the eutrophication gradient is also the result of a collapse of indirect facilitation.

This study experimentally demonstrated the effect of positive interactions between macrophytes in maintaining plant performance and suggested an important role of indirect facilitation for freshwater ecosystems threatened by eutrophication. Indirect facilitation among submerged aquatic plants may play an important role in the maintenance of clear water states and driving thresholds of regime shifts. Therefore, we particularly advocate moving beyond a two-level experimental study to clarify the potential key role of facilitation in driving alternative states (Scheffer \& Carpenter 2003). Studying the consequences of facilitation in freshwater ecosystem may (i) make important contributions to elucidating the relationship between biotic interactions, community dynamics and ecosystem maintenance and (ii) contribute to 'cross-environment comparisons for developing general models of ecology' (Brooker \& Callaway 2009).

\section{Acknowledgements}

This research project was part of the Collaborative Research Center (CRC) no 454 'Littoral of Lake Constance' and was financially supported by the Deutsche Forschungsgemeinschaft (DFG). We thank C. Gebauer and K. Rinke for nutrient and Chl- $a$ measurements, H. Hillebrand and R. Michalet for providing valuable comments on the manuscript and M.A. Harsch and Y. Tao for improving the English. We would also like to thank R.W. Brooker, the associate editor, and two anonymous reviewers for valuable comments on earlier versions of the manuscript.

\section{References}

Bertness, M.D. \& Callaway, R.M. (1994) Positive interactions in communities. Trends in Ecology and Evolution, 9, 191-193. 
Brooker, R.W. \& Callaghan, T.V. (1998) The balance between positive and negative plant interactions and relationship to environmental gradients: a model. Oikos, 81, 196-201.

Brooker, R.W. \& Callaway, R.M. (2009) Facilitation in a conceptual melting pot. Journal of Ecology, 97, 1117-1120

Brooker, R.W., Maestre, F.T., Callaway, R.M., Lortie, C.L., Cavieres, L.A., Kunstler, G. et al. (2008) Facilitation in plant communities: the past, the present and the future. Journal of Ecology, 96, 18-24.

Callaway, R.M. (1995) Positive interactions among plants. Botanical Review, 61, 306-349.

Callaway, R.M. \& King, L. (1996) Temperature-driven variation in substrate oxygenation and the balance of competition and facilitation. Ecology, 77, $1189-1195$

Carpenter, S.R. (2005) Eutrophication of aquatic ecosystems: bistability and soil phosphorus. Proceedings of the National Academy of Sciences, 102 10002-10005.

Chambers, P.A., Barko, J.W. \& Smith, C.S. (1993) Evaluation of invasions and declines of submerged aquatic macrophytes. Journal of Aquatic Plant Management, 31, 218-220.

Choler, P., Michalet, R. \& Callaway, R.M. (2001) Competition and facilitation on gradients in alpine communities. Ecology, 82, 3295-3308.

Connell, J.H. (1978) Diversity in tropical rain forests and coral reefs. Science, 199, 1302-1310.

Cronin, G. \& Lodge, D.M. (2003) Effects of light and nutrient availability on the growth, allocation, carbon/nitrogen balance, phenolic chemistry, and resistance to herbivory of two freshwater macrophytes. Oecologia, 137, 32 41

Engelhardt, K.A.M. \& Richie, M.E. (2002) The effect of aquatic plant species richness on wetland ecosystem processes. Ecology, 83, 2911-2924.

Espeland, E.K. \& Rice, K.J. (2007) Facilitation across stress gradients: the importance of local adaptation. Ecology, 88, 2404-2409.

Falkowski, P.G. \& Raven, J.A. (2007) Aquatic Photosynthesis, 2nd edn. Princeton University press, Princeton, New Jersey.

Gopal, B. \& Goel, U. (1993) Competition and allelopathy in aquatic plant communities. Botanical Reviews, 59, 155-210.

Grime, J.P. (1973) Competitive exclusion in herbaceous vegetation. Nature, 242, 344-347.

Gross, E.M., Feldbaum, C. \& Choi, C. (2002) High abundance of herbivorous Lepidoptera larvae (Acentria ephemerella) on submerged macrophytes in Lake Constance (Germany). Hydrobiologia, 155, 1-21.

Gross, N., Kunstler, G., Liancourt, P., de Bello, F., Suding, K. \& Lavorel, S (2009) Linking individual response to biotic interactions with community structure: a trait-based framework. Functional Ecology, 23, 1167-1178.

Gross, N., Liancourt, P., Choler, P., Suding, K.N. \& Lavorel, S. (2010a) Strain and vegetation effects on local limiting resources explain the outcomes of biotic interactions. Perspective in Plant Ecology, Evolution and Systematic, 12, 949.

Gross, N., Le Bagousse-Pinguet, Y., Liancourt, P., Urcelay, C., Roumet, C. \& Lavorel, S. (2010b) Trait-mediated effect of arbuscular mycorrhiza on the competitive effect and response of a monopolistic species. Functional Ecology, 24, 1122-1132

Grubb, P.J. (1977) The maintenance of species richness in plant communities: the importance of the regeneration niche. Biological Review, 52, 107-145.

Hacker, S.D. \& Gaines, S.D. (1997) Some implications of direct positive interactions for community species diversity. Ecology, 78, 1990-2003.

Hautier, Y., Niklaus, P.A. \& Hector, H. (2010) Competition for light causes plant biodiversity loss after eutrophication. Science, 324, 636-638

Hedges, L.V., Gurevitch, J. \& Curtis, P.S. (1999) The meta-analysis of response ratios in experimental ecology. Ecology, 80, 1150-1156

Hillebrand, H., Gruner, D.S., Borer, E.T., Bracken, M.E.S., Cleland, E.E., Elser, J.J. et al. (2007) Consumer versus resource control of producer diversity depends on ecosystem type and producer community structure. Proceedings of the National Academy of Sciences, 104, 10904-10909.

Holmgren, M. \& Scheffer, M. (2010) Strong facilitation in mild environments: the stress gradient hypothesis revisited. Journal of Ecology, 98, 1269-1275.

James, C., Fisher, J., Russell, V., Collings, S. \& Moss, B. (2005) Nitrate availability and hydrophyte species richness in shallow lakes. Freshwater Biology, 50, 1049-1063.

Jeppesen, E., Sondergaard, M., Lauridsen, T.L., Pedersen, L.J. \& Jensen, L. (1997) Top-down control in freshwater lakes: the role of nutrient state, submerged macrophytes and water depth. Hydrobiologia, 342/343, 151-164

Le Bagousse-Pinguet, Y., Gross, E.M. \& Straile, D. (2011) Release from competition and protection determine the outcome of plant interactions along a grazing gradient. Oikos, in press. DOI: 10.1111/j.1600-0706.2011.19778.x.
Lehmann, A. \& Lachavanne, J.B. (1999) Changes in the water quality of Lake Geneva indicated by submerged macrophytes. Freshwater Biology, 42, 457466.

Liancourt, P., Callaway, R.M. \& Michalet, R. (2005) Stress-tolerance and competitive-response ability determine the outcome of biotic interactions. Ecology, 86, 1611-1618.

Liancourt, P., Viard-Cretat, F. \& Michalet, R. (2009) Contrasting community responses to fertilization and the role of competitive ability of dominant species. Journal of Vegetation Science, 20, 138-147.

Maestre, F.T., Callaway, R.M., Valladares, F. \& Lortie, C.J. (2009) Refining the stress-gradient hypothesis for competition and facilitation in plant communities. Journal of Ecology, 97, 199-205.

Maestre, F.T., Browker, M.A., Escolar, C., Puche, M.D., Soliveres, S., MaltezMouro, S. et al. (2010) Do biotic interactions modulate ecosystem functioning along stress gradients, Insights from semi-arid plant and biological soil crust communities. Philosophical Transactions of the Royal Society B, 365, 2057-2070.

McCauley, E., Downing, J.A. \& Watson, S. (1989) Sigmoid relationship between nutrients and chlorophyll among lakes. Canadian Journal of Fisheries and Aquatic Sciences, 46, 1171-1175,

Meijer, M.L., Jeppesen, E., Van Donk, E. \& Moss, B. (1994) Long-term response to fish-stock reduction in small shallow lakes: interpretation of five-years results of four biomanipulation cases in The Netherlands and Denmark. Hydrobiologia, 276, 457-466.

Michalet, R., Brooker, R.W., Cavieres, L.A., Kikvidze, Z., Lortie, C.J., Pugnaire, F.I. et al. (2006) Do biotic interactions shape both sides of the humped-back model of species richness in plant communities? Ecology Letters, 9, 767-773.

Milchunas, D.G. \& Noy-Meir, I. (2002) Grazing refuges, external avoidance of herbivory and plant diversity. Oikos, 99, 113-130

Moss, B., McGowan, S. \& Carvalho, S. (1994) Determination of phytoplankton crops by top-down and bottom-up mechanisms in groups of English lakes, the West Mid-land meres. Limnology and Oceanography, 39, 1020-1029.

Oksanen, L. \& Oksanen, T. (2000) The logic and realism of the hypothesis of exploitation ecosystems. American Naturalist, 155, 703-723.

Redfield, A.C. (1958) The biological control of chemical factors in the environment. American Scientist, 46, 205-221.

Riis, T. \& Sand-Jensen, K. (2001) Historical changes in species composition and richness accompanying perturbation and eutrophication. Freshwater Biology, 46, 269-280.

Saccone, P., Pages, J.P., Girel, J., Brun, J.J. \& Michalet, R. (2010) Acer negundo invasion along a successional gradient: early direct facilitation by native pioneers and late indirect facilitation by conspecifics. New Phytologist, 187, $831-842$.

Sand-Jensen, K., Pedersen, N.L., Thorsgaard, I., Moeslund, B., Borum, J. \& Brodersen, K.P. (2008) 100 years of vegetation decline and recovery in lake Fure, Denmark. Journal of Ecology, 96, 260-271

Scheffer, M. (1998) Ecology of Shallow Lakes. Chapmann \& Hall, London.

Scheffer, M. \& Carpenter, S. (2003) Catastrophic regime shift in ecosystems: linking theory to observation. Trends in Ecology and Evolution, 18, 648-656.

Scheffer, M., de Redellijkheid, M.R. \& Noppert, F. (1992) Distribution and dynamics of submerged vegetation in a chain of shallow eutrophic lakes. Aquatic Botany, 42, 199-216.

Scheffer, M., Hosper, H.S., Meijer, M.-L., Moss, B. \& Jeppesen, E. (1993) Alternative equilibria in shallow lakes. Trends in Ecology and Evolution, 8, 275-279.

Schmieder, K. (1997) Littoral zone-GIS of Lake Constance: a useful tool in lake monitoring and autoecological studies with submerged macrophytes. Aquatic Botany, 58, 333-346.

Smith, C.S. \& Barko, J.W. (1990) Ecology of Eurasian watermilfoil. Journal of Aquatic Plant Management, 28, 55-64.

Stephen, D., Moss, B. \& Phillips, G. (1997) Do rooted macrophytes increase sediment phosphorus release? Hydrobiologia, 342/343, 27-34

Suding, K.N., Collins, L.S.C., Gough, L., Clark, C., Cleland, E.E., Gross, K.L. et al. (2005) Functional- and abundance-based mechanisms explain diversity loss due to $\mathrm{N}$ fertilization. Proceedings of the National Academy of Sciences, $102,4387-4392$

Tilman, D. (1982) Resource Competition and Community Structure. Princeton University Press, Princeton, New Jersey.

Wolfer, S. \& Straile, D. (2004) Spatio-temporal dynamics and plasticity of clonal architecture in Potamogeton perfoliatus. Aquatic Botany, 78, 307-318

Received 8 June 2011; accepted I November 2011

Handling editor: Rob Brooker 